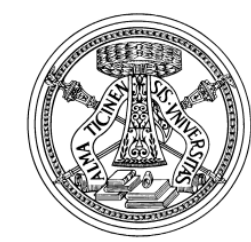

Quaderni di Dipartimento

\title{
Who skims the cream of the Italian graduate crop? Wage-employment versus self-employment
}

\author{
Carolina Castagnetti \\ (Università di Pavia) \\ Luisa Rosti \\ (Università di Pavia)
}

\# 89 (01-09)

Dipartimento di economia politica

e metodi quantitativi

Università degli studi di Pavia

Via San Felice, 5

I-27100 Pavia

Gennaio 2009 


\title{
Who skims the cream of the Italian graduate crop?
}

\author{
Wage-employment versus self-employment \\ Carolina Castagnetti * Luisa Rosti ${ }^{\dagger}$ \\ Università di Pavia Università di Pavia
}

This version: January 2009

\begin{abstract}
This paper tests whether the academic achievement is a significant determinant of the employment status in the Italian labor market: are the new entrepreneurs selected from the top or bottom end of the graduates ability distribution? Is the cream of the graduate crop pulled into selfemployment by the higher expected earnings or are the individuals with lower degree score pushed into entrepreneurship by poor alternatives? Our data show a strong negative relation between academic achievement and self-employment status, i.e. we assess the skimming of the best graduates into wage and salary work.
\end{abstract}

JEL - Classification: J24, J31

\footnotetext{
*Dipartimento di Economia Politica e Metodi Quantitativi, Via San Felice 5, 27100 Pavia, Italy, castca@eco.unipv.it, tel.++390382986217, fax.++390382304226, corresponding author

${ }^{\dagger}$ Dipartimento di Economia Politica e Metodi Quantitativi, Via San Felice 5, 27100 Pavia, Italy, Irosti@eco.unipv.it, tel.++390382986216, fax.++390382304226
} 


\section{Introduction}

This paper tests whether the academic achievement is a significant determinant of the employment status: are the new entrepreneurs selected from the top or bottom end of the graduates ability distribution? Is the cream (the part that rises to the top) of the graduate crop pulled into self-employment by the higher expected earnings or are the individuals with lower degree score pushed into entrepreneurship by poor alternatives (?)?

Previous research on the empirical relation between education and entrepreneurship find an insignificant selection effect. A meta-analysis of 94 academic studies conducted by ? measures the impact of schooling on selfemployment and draws the conclusion that the effect of education on entrepreneurship is neither positive nor negative. ${ }^{1}$

In this paper we provide additional empirical evidence for the Italian labor market. In particular, our data show a strong negative relation between academic achievement and self-employment status, i. e. we assess the skimming of the best graduates into wage and salary work.

This paper has two advantages over previous research. First, in Italy self-employment represents a clear alternative to wage and salary employment because the share of self-employed workers over total employed is above 28 percent. $^{2}$ Moreover, the self-employment rate among graduate workers is about 26 percent, the highest rate in Europe and more than double the share in Denmark, France, Spain, Portugal, Sweden, Netherlands and Finland (?.

Second, our data allow to shift the focus of the relationship between schooling and employment status from the highest level of education completed to more specific measurements like as degree scores and completion speed by majors. To our knowledge, ability as measured by degree performance has rarely been used in previous analyzes of self-employment. As far as we know, only ? consider degree class and A level score. They draw the conclusion that these variables have no significant role to play in their analysis. 


\section{Related Literature}

We focus our analysis on two questions: 1) Why do some people choose selfemployment over wage employment? 2) Why do the best Italian graduates prefer wage-employment? The theoretical literature on entrepreneurship argues that those who choose self-employment are all individuals for whom the use of their ability in entrepreneurial functions guarantees earnings higher than they would otherwise receive $(?)^{3}$. Therefore people in self-employment are related to both entrepreneurial ability and outside options. ? suggest that education enhances individual managerial ability and increases the probability of choosing self-employment because more educated workers tend to be better informed and more efficient at assessing entrepreneurial opportunities. However, this positive effect may be dominated by an opposite (negative) effect of education on entrepreneurship selection. In fact, higher educational performances might generate better outside options in paid employment, and thus depress the likelihood of self-employment as the preferred choice (?).

Our data show that the degree score is higher for employees than it is for the self-employed, even if the graduate starting salary is higher for male self-employed (but not for female self-employed). This positive selection effect into paid work may be due either to the attractiveness of a career prospect ${ }^{4}$ or to the attractiveness of employment protection on young graduates. ${ }^{5}$

The debate on the European labor market regulation has emphasized the negative effect of employment protection legislation on the firms' firing costs (?). In contrast, the results presented here highlight a positive effect deriving to firms from the stability of the employment relationship: it induces jobseekers to compete for vacancies, so that firms can apply selection criteria to screen the best of them (?).

Thus the employment protection legislation may have two consequences on self-employment. First, it may make self-employment an attractive option for low-ability graduates who have failed to pass firms' selection processes, partic- 
ularly if employers attempt to circumvent the negative effect of employment protection legislation by contracting-out work to self-employed contractors (?). ${ }^{6}$ Second, our data show that job protection may induce the best graduates to prefer dependent employment, dissuading the "cream of the crop" from taking up other options as the self-employment status.

As suggested by the referees, we produce separate gender specific estimates because several studies show that female and male entrepreneurs differ in many respects. ${ }^{7}$

The previous literature on gender and entrepreneurship shows that female and male entrepreneurs may differ in their motivations: ? report that males have a higher preference for entrepreneurship than females; ? finds that women choose entrepreneurship in order to achieve a balance between career and personal life/family. ? highlight the desire of women to pursue entrepreneurship for career advancement as well: they suggest that women are motivated to choose entrepreneurship because they experience gender related barriers to their career advancement in paid employment. In this paper we add to previous literature showing that the best female graduates prefer job protection of the subordinate labor contracts to career advancement and flexibility of self-employment.

\section{$3 \quad$ Data and Methodology}

\section{Data}

Our data are derived from the Survey on Labor Market Transitions of University Graduates carried out in 2004 by the Italian National Statistical Office. The Survey is the result of interviewing Italians who graduated from university in 2001 three years after graduation. The retrospective information gathered allows us to analyze both academic performance (final degree grades) and initial entry into the labor market. ${ }^{8}$ The data contain information on the educational curriculum, the occupational status, the student's family 
background and personal characteristics.

In particular, the principal variables contained in the data set can be divided into the following five main groups. (i) University Career and High School Background: including, kind of high school attended, high school mark, other education, university, subject, duration, degree score, accommodation, work during university, post graduate studies,(ii) Work Experience: including, experience in actual work, experience, type of work, net monthly wage,(iii) Work Search: including, kind of work desired, willingness to work abroad, preference over time table, minimum net monthly wage required, (iv) Family Information: including, parents' work, parents' education level, brothers and/or sisters, (v) Personal Characteristics: including, date of birth, sex, marital status, children, country of domicile, country of birth, residence.

Following much of the existing empirical literature, the sample used in this study was constructed in the following way. We restrict the sample to male individuals because of the gender differences in the labor market behavior. Further, we exclude individuals that work in the sector of primary production, in line with ?, ? and ?. We omit individuals who graduated in the field of medicine as their career path is very different from that of other graduates. ${ }^{9}$ Finally, the sample consists of full-time workers only. ${ }^{10}$ We end up with a sample of 5203 individuals, 1065 are self-employed and 4138 employees, a sample self-employment rate of about $20 \%$. Table 1 provides descriptive statistics for the sample used.

Figure ?? shows the empirical distribution of earnings for self-employed and employees. ${ }^{11}$ We observe that the distribution of self-employment earnings exhibits greater dispersion and is more skewed than the employees distribution. As indicated by the tails of the self-employment distribution, about 9 (13) percent of business owners earn more (less) than 2500 (800) euros per month, compared to only 2 (1) percent of employees.

Further evidence of the differences in self-employment and employee net 
monthly earnings distributions is shown in tables 1 and 2. Self-employed people seem to earn more on average than employees do. The standard deviation of the income of the self-employed is also two times higher than for the employees. Table 2 shows the distribution of the net monthly earning by job status. Both tables are consistent with the view that the self-employment typically offers higher earnings but is a more risky option because the increased changes of higher earnings are balanced to some extent by the increased changes of low earnings.

There is now clear evidence in the literature that self-employed workers have more variable and unequal incomes than employees do (?). As an example, all the studies on the distribution of self-employment income explored by ? show that the self-employed are over-represented in both the upper and lower tails of the overall income distribution. However, we observe that in our sample two opposite grounds may explain the self-employed income distribution. From one side we consider only graduate workers. Indeed, the education may reduce the variation in the self-employment earning as stressed by ?. From the other side we take into account a first entry in the job market, i.e. the earnings are sampled at an early stage of the graduate's career. In particular, this sampling may thick the left tail of the self-employed earning distribution where low earnings may merely reflect the initial costs of establishing a business.

In the following, we attempt to show the influence of the individual ability on the choice to become self-employed. To this end, we measure the unobservable ability by means of the degree performance. The degree performance takes into account both the final degree mark and the speed ${ }^{12}$ at which students complete their academic career. Both information are gathered in what we call the "educational performance": edperf.

$$
\text { edperf }=\frac{d s c o r e}{1+0.10 \times \text { years }}
$$

where dscore is the degree mark plus the laude or highest honors when it 
occurs. The number of years in excess (years) used to get the degree is eventually corrected for those having carried out military service during university years. Obviously, the degree scores have been normalized to take into account the different marking scale for each faculty. ${ }^{13}$

Figure 2 shows the cumulative distribution functions of the educational performance (edperf) for employee and self-employed graduates. Our data clearly show a first order stochastic dominance of employees with respect to self-employed. ${ }^{14}$ Hence, when we only consider the effect of the academic achievement on the self employed status we find a clear and strong negative relation. In the following we investigate whether this relation holds also when we control for other variables as individual characteristics (for instance family background) and the potential earning obtained from working in each sector.

\section{Methodology}

We investigate the effect of the educational performance on the choice between self-employment and paid-employment by means of the model of ? and similar to the models estimated by ?, ?, ? and ?. The motivation of the model, which is a standard selection model of the employment status decision, is that the self-employed have a comparative advantage of working in that sector. An individual chooses to work in the self-employed sector if his utility is higher than in the paid-employed sector. Formally, an individual $i$ will choose to be self-employed if:

$$
U_{i}^{s e}-U_{i}^{e} \equiv \alpha_{0}\left(\ln \left(Y_{i}^{s e}\right)-\ln \left(Y_{i}^{e}\right)\right)+\alpha_{1} X_{i}+\epsilon_{i}>0
$$

where the superscripts se and $e$ refer to the self-employment and employed sector, respectively. The utility obtained in each sector, i.e. the choice of sector, depends on personal characteristics, such as social background, risk attitudes, family responsibilities and education (the variables included in $X$ ), ${ }^{15}$ on nonpecuniary utility from independence and on the earnings differential in the two sectors, $Y^{s e}$ and $Y^{e}$, respectively. Because the earnings of an 
individual is only observed in the sector which he or she works, a sample selection problem may arise. This problem is overcome by estimating earnings equations for the self-employed and the paid employed augmented with the appropriate sample selection corrections (Table 4). Therefore, we first estimate a reduced form probit model (Table 5) for the choice of being self-employed and then we make use of this estimation result to eventually correct the earning regression estimation for the sample selection (? two-step procedure). Last, we estimate the structural form probit (Table 5) which includes as regressors also the difference in the natural logarithm of the earnings in the two sectors, $\left(\ln \left(Y_{i}^{s e}\right)-\ln \left(Y_{i}^{e}\right)\right)$.

The structural probit equation is identified by means of variables that appear in the structural probit but not in the earnings equations. These variables should affect the choice to become self-employed/employees but not earnings. ${ }^{16}$ We identify the structural probit by omitting the dummy variable Children from the earnings equations. In fact, while there is no reason to expect that being married should affect earnings, the number of children has been found in several studies, ${ }^{17}$ to be correlated with being self-employed.

At the same time, the identification of the structural probit equation relies also on the exclusion of variables which affect the selection decision only through the earnings equations. Following ? and ? we drop from the structural probit equation the education level dummies of the individual, i.e. the dummy Qualification which assumes a value of 1 whether the graduate workers has attempted further qualification after graduation. We therefore assume that the education level dummies of the individual affects the choice to be selfemployed or not through earnings effects only. Further, we exclude from the structural probit equation the dummy variable Work Experience which indicates whether the individual has started his actual work before the graduation or, more in general, was working before he graduated. 


\section{Results}

? and ? find no statistically significant role for the predicted earnings differential in the estimates of the self-employment decision. In contrast with these results, our data suggest that the earnings distribution provides incentives to be self-employed in line with the findings of ?, ?, ?, ? and ?. The coefficient of the predicted earnings difference used in the structural probit model is positive and significant (see table 5). This implies that the more the predicted self-employment (employees) earnings exceed the predicted employees (self-employed) earnings for a given individual, the more likely that individual is to be self-employed (employee).

We turn now to analyze the influence of the direct effect of ability (as measured by the educational performance) on the entrepreneurial choice. ? find that ability, measured by A-level and degree performance, has no significant role to play. In contrast with this result, we find that the educational performance raises the likelihood to become employee (row 2 of the structural probit equation in table 5), that is we find evidence that high ability graduates are drawn to wage-employment by something other than better earnings. This may be due to the attractiveness of employment protection legislation on young graduates. Traditionally, the Italian standard work contracts have been characterized by high degree of employment protection, mostly against dismissals.

Further, we observe that the educational performance has a positive and significant impact only on the employees earnings (row 3 of table 4 ). ${ }^{18}$ This result seems to be consistent with the presence of a signalling effect of the best graduates in wage-employment. Moreover, our empirical results offer some support for the strong screening hypothesis (SSH) which states that schooling is merely a signal of the productivity for employers. A widely used test to verify the screening hypothesis is to compare the returns to educational performance for the self-employed (the unscreened control group) and employees 
(the screened group). The idea is that self-employed have no need to signal inherent ability and therefore any return they make to education represent a true return to human capital investments. If it turns out that the returns to educational performance for the self-employed are insignificant and the returns to educational performance are significantly positive for employees this would give support for the SSH (see ?, ?, ? and ?).

Table 4 show the estimation results for the earnings' equation in both alternative employment status. Both equations are corrected for possible sample selection bias.

The sample selection terms, lambda, obtained from the reduced form probit, show that there is negative selection bias for the observed earnings of male self-employed only. This means that earnings of males who choose selfemployment are significantly lower from earnings they would have obtained in wage-work. As we ground our model in a utility framework where utility is a function not only of expected income but also of nonpecuniary benefit to be ones' own boss, this result suggests that the self-employed are happier than employees. The empirical results of ? and ? are also consistent with the hypothesis that the self-employed get higher level of job and life satisfaction than employees. This result stands in contrast to those of ? and ? who find evidence of positive selection bias for the observed earnings of employees, but no selectivity bias for the self-employed. In other words, they find that the average earnings of individuals with given measured characteristics who have chosen to be employees is greater than what employee earnings would be for those with the same measured characteristics who choose self-employment.

Last, turning to the structural probit equation, we observe that the family size variable (Children) is signifcant in explaining the choice to become selfemployed. The presence of children reduces the incidence of self-employment for both men and women. This is consistent with the desire to reduce the riskiness of ones income (as shown in fig. 1) by seeking out employment in 
the waged sector (i.e. a steady job entitled with full rights to social security). Conversely, this contrasts with the findings of ?, and ? that children positively influenced the probability of female self-employment due to the need to balance work and childcare commitments. Also ? suggest that the rigidity of waged employment in terms of fixed hours and contractual obligations is less suited to mothers of young children, but in our data job protection (maternity and parental leaves and insurance for sickness or unemployment periods) result more attactive than the flexibility of self-employment.

\section{Conclusion}

A graduate individual will choose wage employment instead of self-employment when the benefit expected from pursuing a career as employee is higher than that of becoming an entrepreneur. Monetary earnings are one of the most important benefit of employment but the choice of a career also depends on preferences and personal attitudes such as specific abilities. As an individual's earnings are only observed in the sector in which he works, sample selection problems may arise. Following ? and ? we separate the direct effect of ability on the entrepreneurial choice from the indirect effect of this characteristic through the expected earnings differential. Our data show that both relative income and ability have a positive role on the choice between self-employment and wage employment: the probability of being an employee depends positively on both the predicted earnings differential and educational performance. We draw the conclusion that firms can skim the cream of the Italian graduate crop and reject low ability individuals pushing them into self-employment, even if they would have otherwise preferred to work as employees. As a consequence, policies based on increasing the returns from self-employment are unlikely to encourage the best graduates to become self-employed at the beginning of their careers. However, the nature of our data set means that these results have to be treated with caution. The graduates are only a short way 
into their careers and they could change the choice between wage employment and self-employment several times during their life work.

\section{Notes}

${ }^{1}$ For example, ? shows that in Europe the probabilities of being selfemployed are lower the more educated an individual is, while the opposite is true in the US. In Italy, as in the U.S., the probability of being self-employed is higher for tertiary educated persons (?).

${ }^{2}$ In Italy the self-employment rate is three times higher than in Denmark and more than double the share in France, Germany, Sweden, Netherlands, Austria and Finland (?).

${ }^{3} \mathrm{~A}$ recent theory formalized in ? and ? posits that an individual who is innately well versed in a variety of fields, i. e. a Jack-of-All-Trades, has a high probability of becoming entrepreneur. Consistent evidence that a balanced skill-mix causally stimulates entrepreneurship is given in ? on German data. On the contrary, ? on Italian data shows that gathering expertise across various subjects does not increase the chances of becoming entrepreneur.

${ }^{4} \mathrm{~A}$ referee suggests this hypothesis, that we cannot neither confirm nor reject because our data refers to individuals with a very short career advancement three years after graduation.

${ }^{5}$ Traditionally, the Italian standard work contracts have been characterized by high degree of employment protection, mostly against dismissals. According to the ?'s Employment Outlook, Italy ranked first in terms of strictness of the regulation of permanent contracts during the 1990's.

${ }^{6}$ ? finds only very limited evidence to support the hypothesis that stricter 
employment protection legislation promotes self-employment in OECD countries.

${ }^{7}$ For example, female entrepreneurs have been found to be more educated either in the U.K. ? and in Italy ( ?). Also ? find substantive differences in job creating capability across gender and education that we cannot verify with our data set.

${ }^{8}$ The graduate population of 2001 consisted of 155.664 individuals (67.913 males and 87.751 females). The ISTAT survey was based on a $28 \%$ sample of these students and was stratified on the basis of degree course taken and by the sex of the individual student. The response rate was about $67.6 \%$, yielding a data-set containing information on 26.006 graduates.

${ }^{9}$ After having obtained their degree in medicine, in general the students carry out a specialist activity which lasts at least three years.

${ }^{10}$ Following ? we define the full-time workers as those who worked more than 30 hours per week.

${ }^{11}$ The estimate is based on a normal kernel function.

${ }^{12}$ In the Italian education system, each faculty only sets a minimum number of years in which to obtain a degree. A consequence is that there is a high dispersion in the age at which students graduate. The speed of completion of the academic career is, therefore, together with the final mark, an important component of the educational performance.

${ }^{13}$ The final degree score ranges from 66 to 110 (for some Universities the maximum mark awarded is 100). According to each faculty internal ruling a laude (distinction) may be assigned to candidates with a 110/110 mark for recognition of the excellence of their thesis (in this analysis the 110 cum laude was transformed to 113). 
${ }^{14}$ First-order stochastic dominance is a possible ordering between two stochastic distributions. Let $F(x)$ and $M(x)$ denote the cumulative distribution functions of the educational performance $x$ for female and male students, respectively. F first-order stochastically dominates $\mathrm{M}$ if and only if for every possible educational performance $x, F(x) \leq M(x)$. This means that for every possible value of $x$, the probability of getting a educational performance that high is never better in $\mathrm{M}$ than in $\mathrm{F}$.

${ }^{15}$ See $?$.

${ }^{16}$ These variables should be uncorrelated with the error terms of the earnings equation but have a strong effect on selectivity. See ?.

${ }^{17}$ See, for instance ? and ?.

${ }^{18}$ This result is in line with the findings of ?, ?, ? and ?.

\section{References}


Table 1: Descriptive Statistics

\begin{tabular}{llccc}
\hline Males & \multicolumn{2}{c}{ Employees } & \multicolumn{2}{c}{ Self-employed } \\
& & & & \\
\hline & Mean & Standard deviation & Mean & Standard deviation \\
\hline Edperf & & & & \\
ln earnings & 83.408 & 17.171 & 80.798 & 16.901 \\
Father self-employed & 0.119 & 0.103 & 3.131 & 0.199 \\
Industrial Sector & 0.361 & & 0.372 & \\
Qualification & 0.012 & & 0.139 & \\
Work Experience & 0.607 & & 0.004 & \\
& & & 0.642 & \\
Females & & Employees & & Self-employed \\
& Mean & Standard deviation & Mean & Standard deviation \\
\hline & & & & \\
\hline & 84.386 & 17.909 & 82.722 & 17.992 \\
Edperf & 3.041 & 0.115 & 3.024 & 0.201 \\
ln earnings & 0.277 & & 0.372 & \\
Father self-employed & & 0.075 & \\
Industrial Sector & 0.177 & & 0.009 & \\
Qualification & 0.011 & & 0.633 & \\
Work Experience & 0.669 & & & \\
\hline \hline
\end{tabular}

Industrial Sector: A dummy taking the value of 1 if the graduate is working in the industrial sector.

Work Experience: A dummy taking the value of 1 if the graduate either was working during the university or has started the actual work before graduating.

Qualification: A dummy taking the value of 1 if the graduate has obtained a postgraduated certificate of education.

Table 2: Relative frequency distribution of net monthly earnings by job status

\begin{tabular}{lcccc}
\hline \multicolumn{4}{c}{ Males } & \multicolumn{2}{c}{ Females } \\
& self-employed & employees & self-employed & employees \\
\hline 450 & $0.18 \%$ & $0.05 \%$ & & \\
600 & $5.68 \%$ & $0.23 \%$ & & \\
800 & $7.01 \%$ & $0.73 \%$ & & \\
1000 & $18.72 \%$ & $12.27 \%$ & & \\
1400 & $26.26 \%$ & $57.26 \%$ & & \\
1800 & $21.47 \%$ & $22.02 \%$ & & \\
2000 & $10.56 \%$ & $3.95 \%$ & & \\
2300 & $1.33 \%$ & $1.71 \%$ & & \\
2600 & $5.06 \%$ & $1.05 \%$ & \\
2800 & $0.35 \%$ & $0.11 \%$ & \\
2950 & $0.18 \%$ & $0.02 \%$ & \\
3300 & $3.19 \%$ & $0.59 \%$ & \\
\hline \hline
\end{tabular}




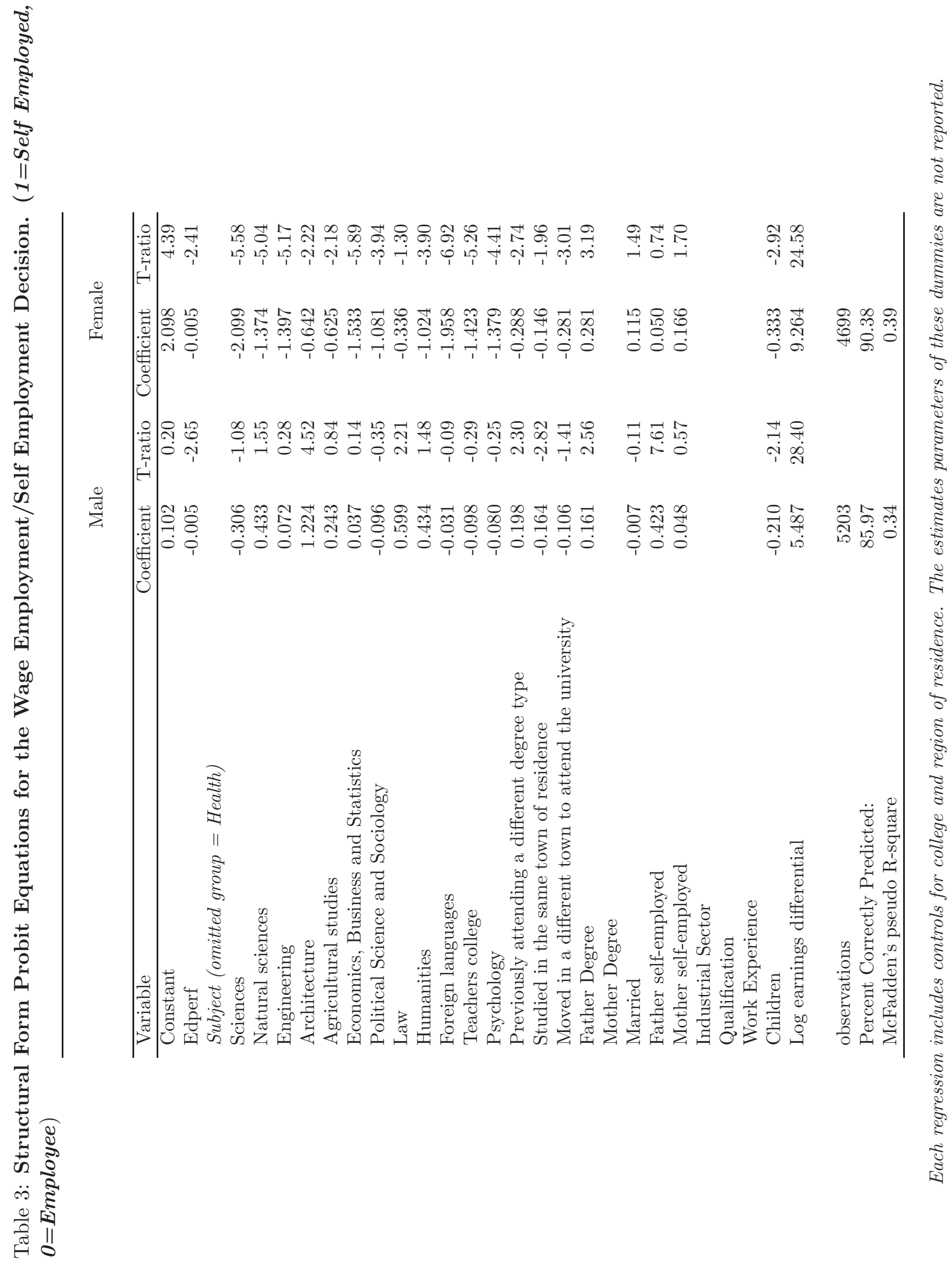




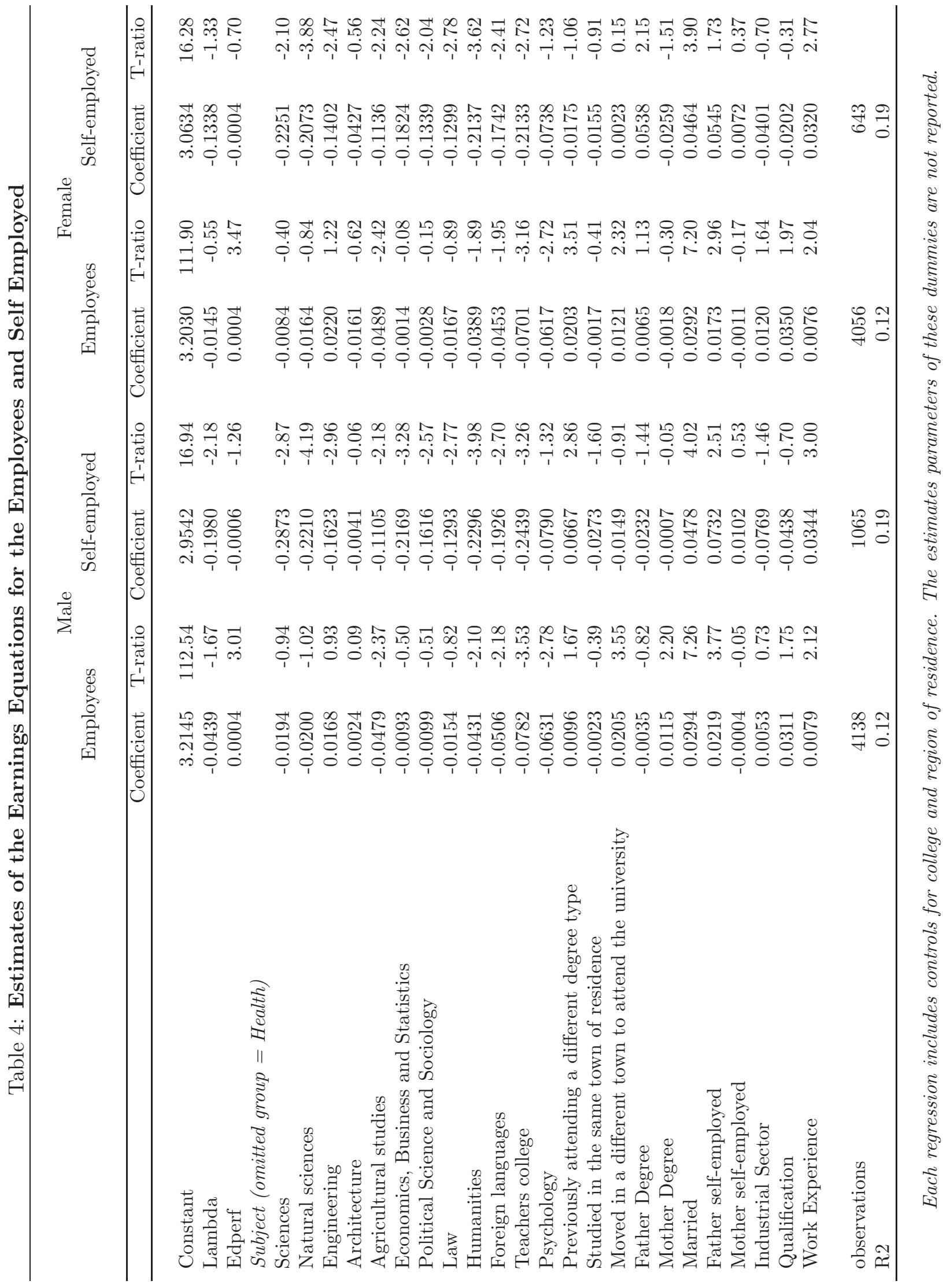




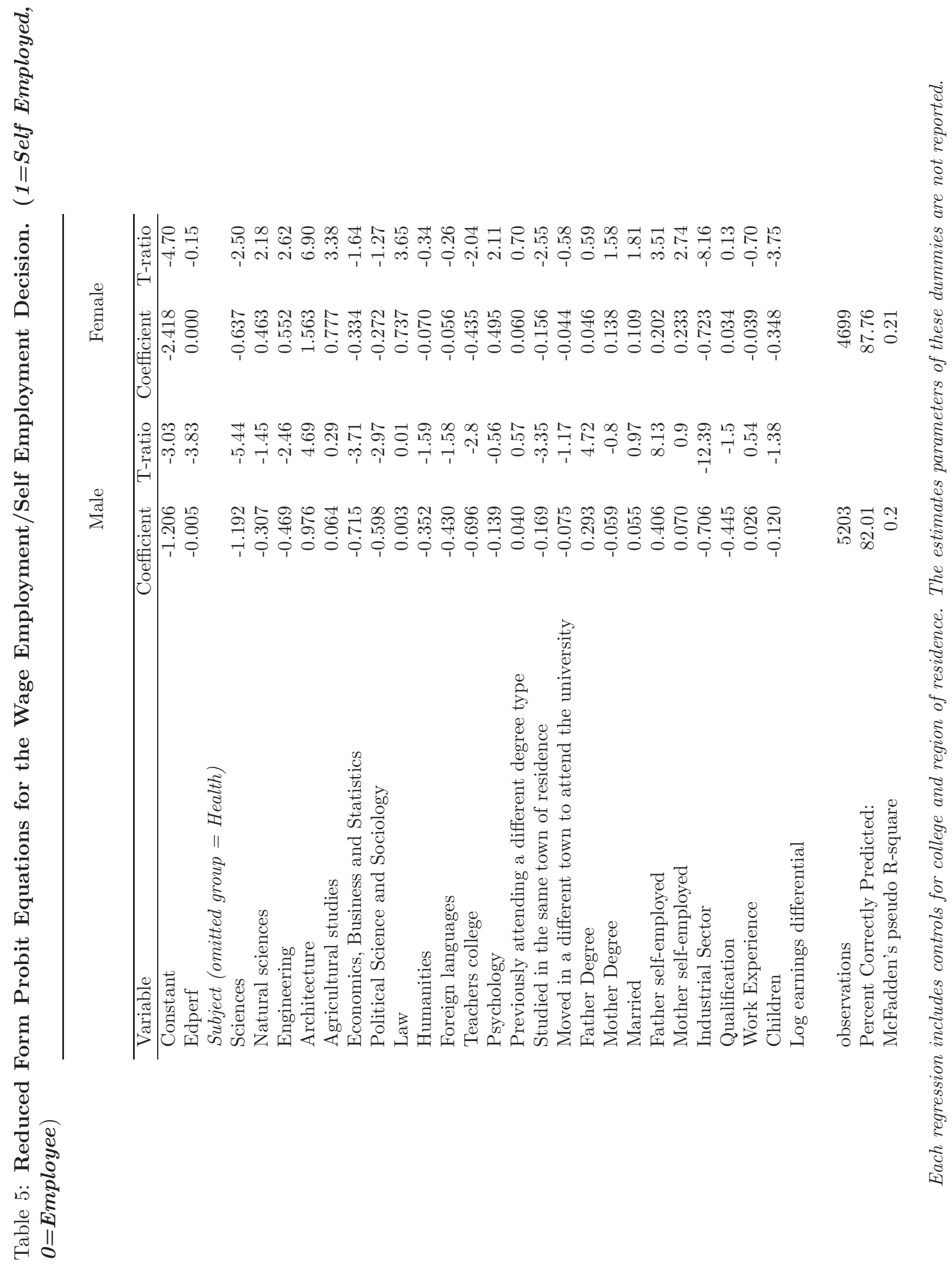


Figure 1: Empirical distribution of earnings for employees and self-employed

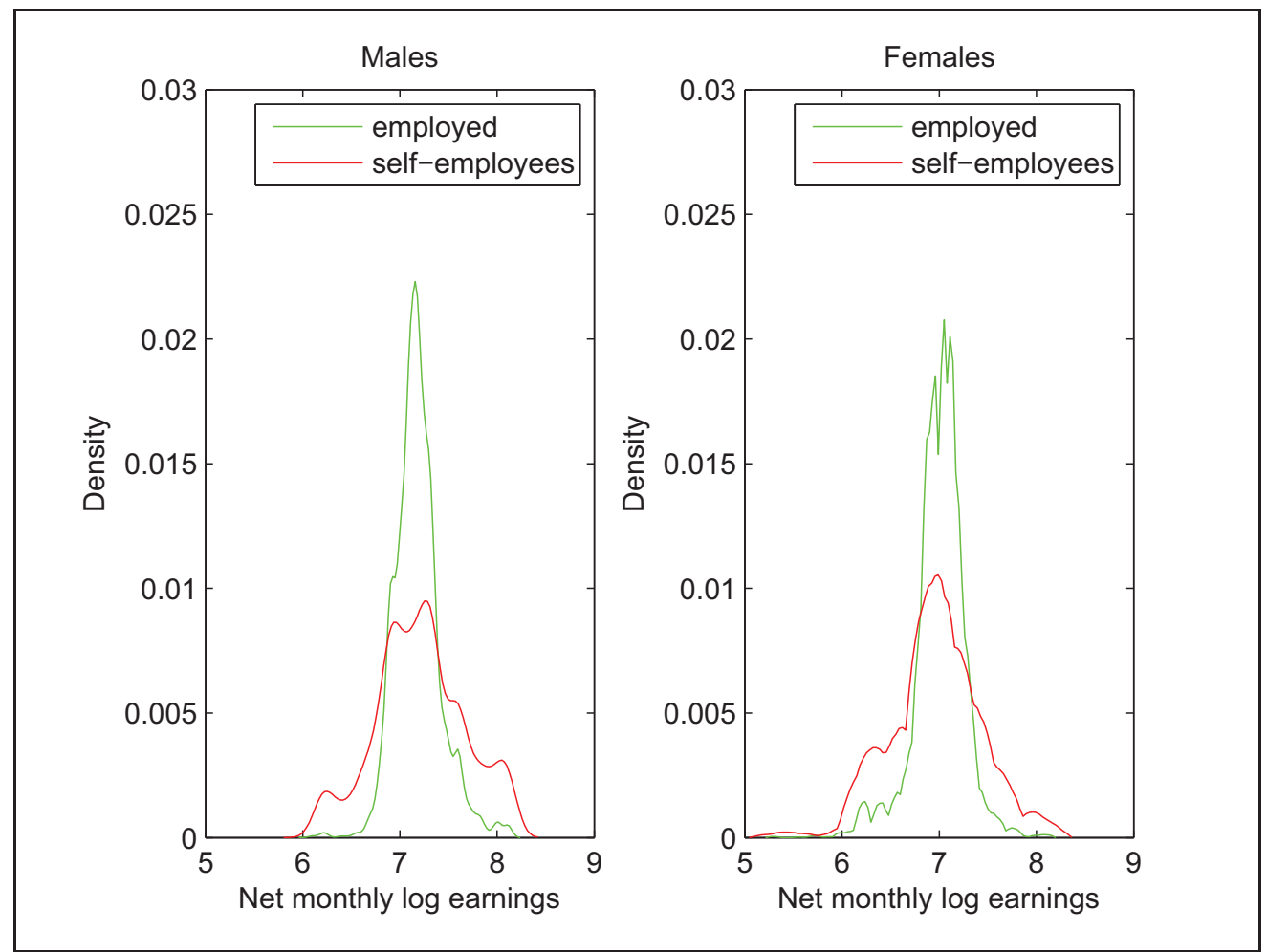

Figure 2: Cumulative distribution functions of the educational performance for employees and self-employed

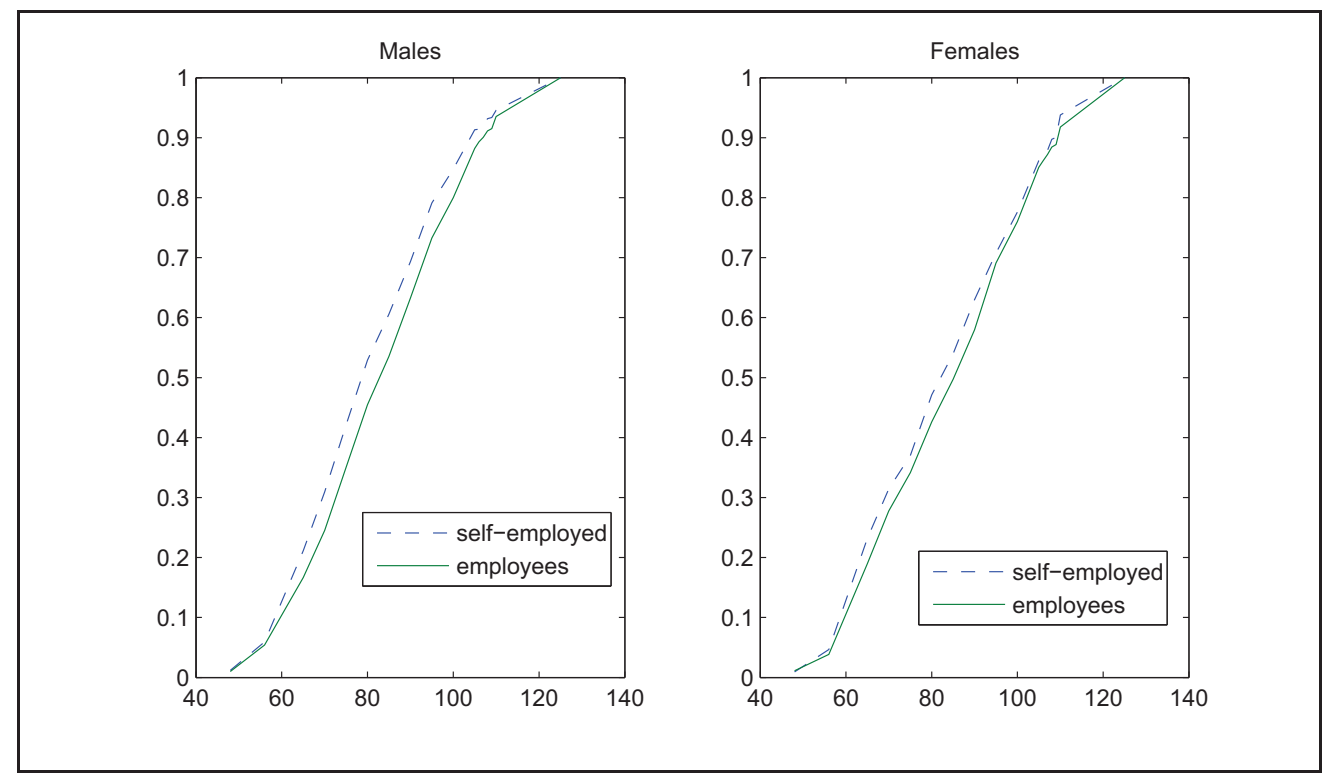

